\title{
Membrane transport of camptothecin: facilitation by human P-glycoprotein (ABCBI) and multidrug resistance protein 2 (ABCC2)
}

\author{
Anita K Lalloo1, Feng R Luo ${ }^{1,3}$, Ailan Guo ${ }^{1,4}$, Pankaj V Paranjpe ${ }^{1}$, Sung- \\ Hack Lee ${ }^{1}$, Viral Vyas ${ }^{2}$, Eric Rubin ${ }^{2}$ and Patrick J Sinko*1,2
}

Address: ${ }^{1}$ Department of Pharmaceutics, Ernest Mario School of Pharmacy, Rutgers, The State University of New Jersey, Piscataway, New Jersey, USA, ${ }^{2}$ The Cancer Institute of New Jersey, New Brunswick, New Jersey, USA, ${ }^{3}$ Bristol Myers Squibb Co., Princeton, New Jersey, USA and ${ }^{4}$ Hoffmann-La Roche, Department of Discovery Pharmacology, Nutley, New Jersey, USA

Email: Anita K Lalloo - lalloo@eden.rutgers.edu; Feng R Luo - roger.luo@bms.com; Ailan Guo - AILAN.GUO@ROCHE.COM; Pankaj V Paranjpe - paranjpe@eden.rutgers.edu; Sung-Hack Lee - sung-hack.lee@rutgers.edu; Viral Vyas - amy@cop.rutgers.edu; Eric Rubin - ehrubin@umdnj.edu; Patrick J Sinko* - sinko@rci.rutgers.edu

* Corresponding author

Published: 04 May 2004

BMC Medicine 2004, 2:16

This article is available from: http://www.biomedcentral.com/l74I-70I5/2/16

(c) 2004 Lalloo et al; licensee BioMed Central Ltd. This is an Open Access article: verbatim copying and redistribution of this article are permitted in all media for any purpose, provided this notice is preserved along with the article's original URL.
Received: 02 December 2003

Accepted: 04 May 2004

\begin{abstract}
Background: The purpose of the present study was to continue the investigation of the membrane transport mechanisms of 20 -(S)-camptothecin (CPT) in order to understand the possible role of membrane transporters on its oral bioavailability and disposition.

Methods: The intestinal transport kinetics of CPT were characterized using Caco-2 cells, MDCKII wild-type cells and MDCKIl cells transfected with human P-glycoprotein (PGP) (ABCBI) or human multidrug resistance protein 2 (MRP2) (ABCC2). The effects of drug concentration, inhibitors and temperature on CPT directional permeability were determined.

Results: The absorptive (apical to basolateral) and secretory (basolateral to apical) permeabilities of CPT were found to be saturable. Reduced secretory CPT permeabilities with decreasing temperatures suggests the involvement of an active, transporter-mediated secretory pathway. In the presence of etoposide, the CPT secretory permeability decreased $25.6 \%$. However, inhibition was greater in the presence of PGP and of the breast cancer resistant protein inhibitor, GFI209/8 (52.5\%). The involvement of additional secretory transporters was suggested since the basolateral to apical permeability of CPT was not further reduced in the presence of increasing concentrations of GFI20918. To investigate the involvement of specific apically-located secretory membrane transporters, CPT transport studies were conducted using MDCKII/PGP cells and MDCKII/MRP2 cells. CPT carrier-mediated permeability was approximately twofold greater in MDCKII/PGP cells and MDCKII/MRP2 cells than in MDCKII/wild-type cells, while the apparent $K_{m}$ values were comparable in all three cell lines. The efflux ratio of CPT in MDCKII/PGP in the presence of $0.2 \mu \mathrm{M}$ GFI209I 8 was not completely reversed (3.36 to 1.49). However, the decrease in the efflux ratio of CPT in MDCKII/MRP2 cells (2.3I to I.03) suggests that CPT efflux was completely inhibited by MK57I, a potent inhibitor of the Multidrug Resistance Protein transporter family.
\end{abstract}


Conclusions: The current results provide evidence that PGP and MRP2 mediate the secretory transport of CPT in vitro. However, the involvement of other transporters cannot be ruled out based on these studies. Since these transporters are expressed in the intestine, liver and kidney variations in their expression levels and/or regulation may be responsible for the erratic oral absorption and biliary excretion of CPT observed in human subjects.

\section{Background}

20-(S)-camptothecin (CPT) is a cytotoxic alkaloid extracted from the Chinese tree Camptotheca acuminata. It has been shown to exhibit potent antitumor activity in several experimental tumor types [1]. In the 1970s, however, due to the poor aqueous solubility of CPT $(2.5 \mu \mathrm{g} /$ $\mathrm{ml}$ ), the water-soluble sodium salt NSC100880 was formulated for use in phase I and phase II clinical trials. The results of these trials were disappointing, demonstrating minimal antitumor activity with severe and unpredictable toxicity. This led to the discontinuation of the clinical studies [2]. Failure of the early CPT trials was attributed to the conversion of the pharmacologically active CPT-lactone form to the toxic and inactive carboxylate form in the dosage that was administered to patients [3]. Interest in CPT was revived in the late 1980s for several reasons: the identification of the enzyme topoisomerase I as the major cellular target of CPT [4], the discovery of overexpressed levels of topoisomerase I in tumor cells relative to normal cells [5], the elucidation of the structure-activity relationship of CPT [3], and the potency of several CPT analogs in various malignant cell lines. Two water-soluble derivatives of CPT, irinotecan (СРT-11) and topotecan (ТРT), have received approval for use in the USA from the Food and Drug Administration. Various CPT prodrugs are currently being evaluated in clinical trials.

Camptothecins are cell cycle specific, demonstrating greatest activity in the S-phase. They reversibly stabilize the cleavable complex formed between topoisomerase I and DNA, thus arresting single-strand DNA replication and causing breaks in the double strands. Prolonged or repetitive exposure to these drugs is therefore necessary to increase cell killing since the S-phase is a short phase of the cell cycle. Preclinical and clinical studies have shown that prolonged exposure to CPT and its analogs, through either continuous intravenous infusion or oral administration, results in optimal therapeutic activity [6-8]. The oral delivery route is preferable due to patient compliance considerations, decreased vascular access complications, convenience and low cost. However, clinical evaluation of orally administered CPT indicated variability in the area under the curve (164\%) and the bioavailability (10-fold) [9]. Physicochemical factors such as solubility and dissolution as well as physiological factors (e.g. intestinal absorptive and secretory permeability and first-pass metabolism) are thought to be responsible for variations in the rate and extent of absorption. For CPT and its analogs, however, physicochemical factors are less likely to play a crucial role since erratic bioavailability was also observed with both polar (CPT-11 and TPT) and nonpolar (9-nitrocamptothecin) analogs [10-12]. The observed variability in the area under the curve for CPT-11 and TPT was reported as 50\% and $41 \%$, respectively, while peak blood concentrations ranged from $26 \mathrm{ng} / \mathrm{ml}$ to $517 \mathrm{ng} / \mathrm{ml}$ for 9-nitrocamptothecin. In addition, CPT undergoes substantial biliary excretion resulting in micellar solubilization and complete dissolution of the drug, thus overcoming the solubility limitations [13].

Due to the expression of various secretory membrane transporters (e.g. breast cancer resistant protein [BCRP], human Multidrug Resistance Protein [MRP1-MRP3], Pglycoprotein [PGP]) in the intestine, we postulated that CPT might be a substrate for these efflux transporters. We have therefore initially focused on two well-studied membrane transporters, PGP (ABCB1) and MRP2 (ABCC2). Variations in the intestinal expression and activity of PGP and/or MRP2 may contribute to the erratic bioavailability observed in human subjects. It is also possible that MRP1, MRP3 and BCRP play a role in CPT transport; however, given the lack of specific inhibitors, this remains to be determined. For example, BCRP, a recently identified member of the family of ATP-dependent drug efflux proteins, is a half-transporter expressed in the placenta, the canalicular membranes of the liver, the apical region of the epithelium of the small and large intestine and the ovaries. It appears to play a protective and excretory role similar to many other $\mathrm{ABC}$ transporters and thus may also contribute to the poor oral bioavailability of the CPTs. Several studies have demonstrated that BCRP is an efficient transporter of the CPT analog TPT [14-16]. It also mediates the transport of 9-aminocamptothecin [16]. However, there is no conclusive evidence to date of whether CPT is a substrate for BCRP. Studies are presently being conducted in our laboratory to confirm the role of BCRP in CPT absorption and also to identify other transporters that may be responsible for the low and erratic bioavailability of this drug.

To further elucidate the mechanisms of CPT uptake and disposition, CPT transport kinetics were investigated using Caco- 2 cells, a cell model commonly used as a human enterocyte surrogate, and in MDCK II cells 
overexpressing human transporters (MDCK II/wild-type [wt] cells, MDCK II/PGP cells, and MDCK II/MRP2 cells) in order to study CPT interactions with individual transporters.

\section{Methods \\ Materials}

Camptothecin and etoposide were purchased from Sigma (St Louis, MO, USA) and $\left[{ }^{3} \mathrm{H}\right] \mathrm{CPT}$ was purchased from Moravek Biochemicals (La Brea, CA, USA). Dr Polli kindly donated GF120198 (GlaxoSmithKline Inc., Research Triangle Park, NC, USA), and MK571 was provided by Dr Koch (Merck Co. Inc., Rahway, NJ, USA). PGP and MRP2 antibodies (mAb) C219 and MRP2 H-17 were obtained from Signet Laboratories (Dedham, MA, USA). All other materials were purchased from Fisher (Fair Lawn, NJ, USA) or Sigma and were used as received.

\section{Cell culture}

Caco-2 cells were obtained from the American Type Culture Collection (Rockville, MD, USA) and were frozen at $80^{\circ} \mathrm{C}$. Four weeks prior to the experiment, cells from passage number 20 were cultured in an atmosphere of $95 \%$ air and $5 \% \mathrm{CO}_{2}$ at $37^{\circ} \mathrm{C}$ in Dulbecco's Modified Eagle's medium supplemented with 10\% fetal bovine serum, 1\% nonessential amino acids, and $2 \%$ penicillin-streptomycin. After harvesting at $90 \%$ confluency, the cells were seeded on Snapwell ${ }^{\circledast}$ polycarbonate filter inserts (Corning Costar Corporation, Cambridge, MA, USA) at a density of 45,000 cells $/ \mathrm{cm}^{2}$ and were grown for 21 days. MDCK II/wt cells, MDCK II/PGP cells and MDCK II/MRP2 cells were provided by Dr Borst (The Netherlands Cancer Institute, Amsterdam, The Netherlands) and frozen at $-80^{\circ} \mathrm{C}$. Four weeks prior to the experiment, cells from passage number 10 were cultured in a similar manner to that described for the Caco-2 cells. The cells were harvested at 90\% confluency, and were seeded onto Transwell ${ }^{\circledR}$ polycarbonate filter inserts (Corning Costar Corporation) at a density of 67,000 cells $/ \mathrm{cm}^{2}$ and were grown for 3 days.

\section{Diffusion studies}

Drug transport across Caco-2 cells was conducted in sideby-side diffusion chambers (Harvard Apparatus Inc., Holliston, MA, USA). The chambers were prewarmed to $37^{\circ} \mathrm{C}$ prior to mounting the Snapwell polycarbonate filter inserts with a monolayer of fully differentiated Caco-2 cells. The donor (apical $[\mathrm{AP}]$ ) and the receptor (basolateral $[\mathrm{BL}])$ compartments were filled with the appropriate buffers. The donor buffer was MES Ringer's buffer ( $\mathrm{pH}$ 6.5) and the receptor buffer was Ringer's glucose buffer (pH 7.4), $290 \mathrm{mOsm} / \mathrm{kg}$. To minimize the effect of the aqueous boundary layer, the fluid in the chambers was circulated using a gas lift mechanism with $5 \% \mathrm{CO}_{2}$ and $95 \% \mathrm{O}_{2}$ at a flow rate of $10 \mathrm{ml} / \mathrm{min}$. Drug transport across MDCKII cell monolayers was conducted in Transwell plates, which were placed on an orbital shaker (40 rpm) to reduce the influence of the aqueous boundary layer. Both the donor and receptor compartments were filled with Hank's Balanced Salts Buffer (pH 7.4, $10 \mathrm{mM}$ Hepes). The drug solution (spiked with a trace amount of $\left[{ }^{3} \mathrm{H}\right] \mathrm{CPT}$ to achieve a specific activity of $0.2 \mu \mathrm{Ci} / \mathrm{ml}$ ) was placed in the donor chamber. Samples were removed from the receptor chamber at 30, 45, 60, 75, 90, $105 \mathrm{~min}$, followed by immediate replacement of an equivalent volume of prewarmed buffer. The integrity of the cell monolayer was evaluated before and after the experiment by measuring the transepithelial electrical resistance and $\left[{ }^{14} \mathrm{C}\right]$ mannitol transport. Transepithelial electrical resistance measurements of $300-350 \Omega \mathrm{cm}^{2}$ and mannitol permeability values $<1 \times 10^{-6} \mathrm{~cm} / \mathrm{s}$ indicated that the monolayer integrity was not compromised.

Various kinetic studies were conducted to elucidate the transport pathways (passive and carrier-mediated) of CPT across the intestinal barrier model. The concentration dependence was evaluated by investigating the BL to AP (secretory) transport of $\mathrm{CPT}$ at concentrations ranging from $0.2 \mu \mathrm{M}$ to $100 \mu \mathrm{M}$. The effect of decreasing temperatures on the secretory efflux of CPT was investigated at 4, $10,15,25$ and $37^{\circ} \mathrm{C}$. To delineate the multiple mechanisms involved in the efflux of CPT, permeability was measured in Caco- 2 cells in the presence of the mixed mechanism efflux inhibitor (etoposide) and the PGP and BCRP inhibitor (GF120918). Efflux of CPT was studied at various substrate concentrations $(0.2-1.0 \mu \mathrm{M})$ and at two fixed etoposide concentrations (100 and $200 \mu \mathrm{M})$.

To further elucidate the possible involvement of other transporters in the efflux of CPT, studies were conducted across MDCK II cells transfected with the MDR1 or MRP2 genes. Transport of CPT was evaluated across MDCK II/ PGP cells and MDCK II/MRP2 cells in the presence of the PGP and BCRP inhibitor GF120918 (0.2 $\mu \mathrm{M})$ and of the MRP family inhibitor MK571 (200 $\mathrm{MM})$, respectively. Control studies were performed in MDCKII/wt cells to account for passive transport and transport by means of endogenous (i.e. canine) transporters.

The effective permeability, $P_{\text {eff }}(\mathrm{cm} / \mathrm{s})$ was determined using the equation: $P_{\text {eff }}=\left(V_{\mathrm{r}} / A \times C_{\mathrm{o}}\right) \times \mathrm{d} C / \mathrm{d} t$, where $V_{\mathrm{r}}$ is the volume of the receptor chamber, $A$ is the surface area of the filter, $C_{0}$ is the initial drug concentration, and $\mathrm{d} C / \mathrm{d} t$ is the linear slope of the drug concentration in the receptor chamber versus the time after correcting for dilution. Using nonlinear regression software (Scientist version 2.01; Micromath, Salt Lake City, UT, USA), the Michaelis-Menten kinetic values were determined using the equation: $P_{\text {eff }}=P_{\mathrm{c}} /\left(1+C / K_{\mathrm{m}}\right)+P_{\mathrm{m}}$, where $P_{\mathrm{c}}$ is the carrier permeability $\left(=J_{\max } / K_{\mathrm{m}}\right), K_{\mathrm{m}}$ is the Michaelis- 
Menten constant, and $P_{\mathrm{m}}$ is the nonsaturable passive diffusion permeability.

The energy dependence of the efflux transport process for CPT was determined by calculating the apparent activation energy $\left(E_{\mathrm{a}}\right)$ from an Arrhenius plot $\left(\log P_{\text {eff }}\right.$ versus $1 /$ $T$, where $T$ is the absolute temperature $\left[T^{\circ} \mathrm{C}+273.16^{\circ} \mathrm{C}\right]$ and $R$ is the gas constant [0.001987 kcal/deg mole]), using the equation: slope $=-E_{\mathrm{a}} / 2.303 R$.

A Lineweaver-Burk plot (reciprocal of flux $\left[1 / P_{\mathrm{eff}} \mathrm{x} C\right]$ versus reciprocal of substrate concentration $[1 / C]$ ) was constructed to determine the type of inhibition observed when CPT was co-incubated with the efflux transport inhibitor, etoposide. The inhibition constant $\left(K_{\mathrm{i}}\right)$ was determined from a secondary plot of the slope of the Lineweaver-Burk plots versus the corresponding inhibitor concentrations. The intersection of the least-square linear regression line with the $x$ axis yields the $K_{\mathrm{i}}$ value. To confirm the type of inhibition, Eadie-Hofstee plots were also constructed. Statistical tests were performed using Jandel Sigma Stat version 2.0 (Jandel Scientific Corp. San Raphael, CA, USA) with a minimum $P$ value of 0.05 . One-way analysis of variance and Tukey tests were performed on the permeability data. All data are reported as the mean \pm standard deviation unless otherwise noted. Weighted nonlinear regression was performed using Scientist version 2.01 with a weighting factor of $1 /$ standard deviation.

Validation of the transfected cell lines by regular confirmation of the expression levels is imperative as the transfection may not be complete or the cells may lose expression over time or with passaging. Immunoblotting was used to confirm the presence of the transporters of interest in the MDCK II engineered cell lines. Expression of PGP and MRP2 in MDCK II cells was confirmed using western blot analysis. MDCK II/PGP cells, MDCK II/ MRP1 cells and MDCK II/MRP2 cells were harvested after culturing for 4 days and were lysed in lysis buffer. Ten micrograms of protein were size fractionated in a polyacrylamide gel containing 7\% SDS and were transferred to a nitrocellulose membrane. The blots were incubated with antibodies to PGP (C219) and MRP2 (MRP2 H-17), and were subsequently incubated with anti-mouse or antigoat immunoglobulin, respectively. PGP and MRP2 were detected using an enhanced chemiluminescence system (Amersham, Downers Grove, IL, USA). PGP and MRP2 transporter protein was also confirmed in MDCK II cells using western and Slot blots, and was previously published by our group [17].

\section{Results \\ Concentration dependence of CPT absorptive and secretory permeability across Caco-2 cells}

To determine the apparent transport kinetics of CPT, BL to $\mathrm{AP}$ transport and AP to BL transport of CPT was investigated at concentrations ranging from 0.2 to $100 \mu \mathrm{M}$. The absorptive and secretory permeabilities of CPT were found to be concentration dependent, with the secretory $\mathrm{P}_{\text {eff }}(\mathrm{BL}-\mathrm{AP})$ of CPT decreasing from $2.6 \times 10^{-5}$ to $1.3 \times 10^{-}$ $5 \mathrm{~cm} / \mathrm{s}$ while the absorptive $\mathrm{P}_{\text {eff }}$ of CPT decreased from 8.5 $\times 10^{-5} \mathrm{~cm} / \mathrm{s}$ to $3.6 \times 10^{-5} \mathrm{~cm} / \mathrm{s}$ with increasing drug concentrations (Fig. 1a). Complete saturation of the transporters was not achieved at the highest concentration of CPT studied due to the limited aqueous solubility of the drug. However, it was possible to estimate the passive membrane permeability for CPT (secretory passive membrane permeability, $P_{\mathrm{m}}=\sim 3.5 \times 10^{-6} \mathrm{~cm} / \mathrm{s}$; absorptive influx, $P_{\mathrm{m}}$ $=4.3 \times 10^{-6} \mathrm{~cm} / \mathrm{s}$ ) by conducting the study at low temperature $\left(4^{\circ} \mathrm{C}\right)$ since the active transport of drugs across cells is minimized at low temperatures [18].

$K_{\mathrm{m}}$ and $P_{\mathrm{c}}$ for CPT secretory efflux were estimated to be $132.9 \pm 12.2 \mu \mathrm{M}$ and $2.1 \pm 0.1 \times 10^{-5} \mathrm{~cm} / \mathrm{s}$, respectively, using weighted nonlinear regression and the aforementioned equation for the Michaelis-Menten parameters. These values indicate a low-affinity, high-capacity intestinal efflux transport system for CPT. Similarly, the $K_{\mathrm{m}}$ and $P_{\mathrm{c}}$ values for CPT absorptive transport were estimated to be $6.9 \pm 0.4 \mu \mathrm{M}$ and $31.2 \pm 6.9 \mu \mathrm{M}$ respectively (Table 1 ). The absorptive transport (AP-BL) of CPT across Caco-2 cells was concentration dependent and was significantly higher than secretory transport, suggesting the presence of a dominating absorptive transporter located on either the $\mathrm{BL}$ or AP domains or both. Although the investigation of the absorptive transport of CPT was the focus of our earlier investigation [19], this may have to be re-examined given the recently described role of MRP1 in the absorptive transport of other drugs [17].

To determine whether CPT efflux was an active (i.e. energy dependent) process and to estimate the passive permeability component, the BL to AP transport was investigated at various temperatures ranging from $4{ }^{\circ} \mathrm{C}$ to $37^{\circ} \mathrm{C}$. It was observed that the efflux $P_{\text {eff }}$ of CPT decreased as the temperature was reduced. The energy of activation $\left(E_{\mathrm{a}}\right)$ was estimated to be $\sim 11.3 \mathrm{kcal} / \mathrm{mole}$ from the Arrhenius plot (Fig. 2). Since activation energies greater than $4 \mathrm{kcal} / \mathrm{mole}$ are suggestive of active membrane transport [20], the secretory permeability of CPT appears to occur by an active and energy-dependent mechanism.

\section{Inhibition of CPT efflux across Caco-2 cells}

The concentration and temperature dependency studies suggest that active transporters possibly mediate the efflux of CPT. To confirm this hypothesis, BL to AP transport of 


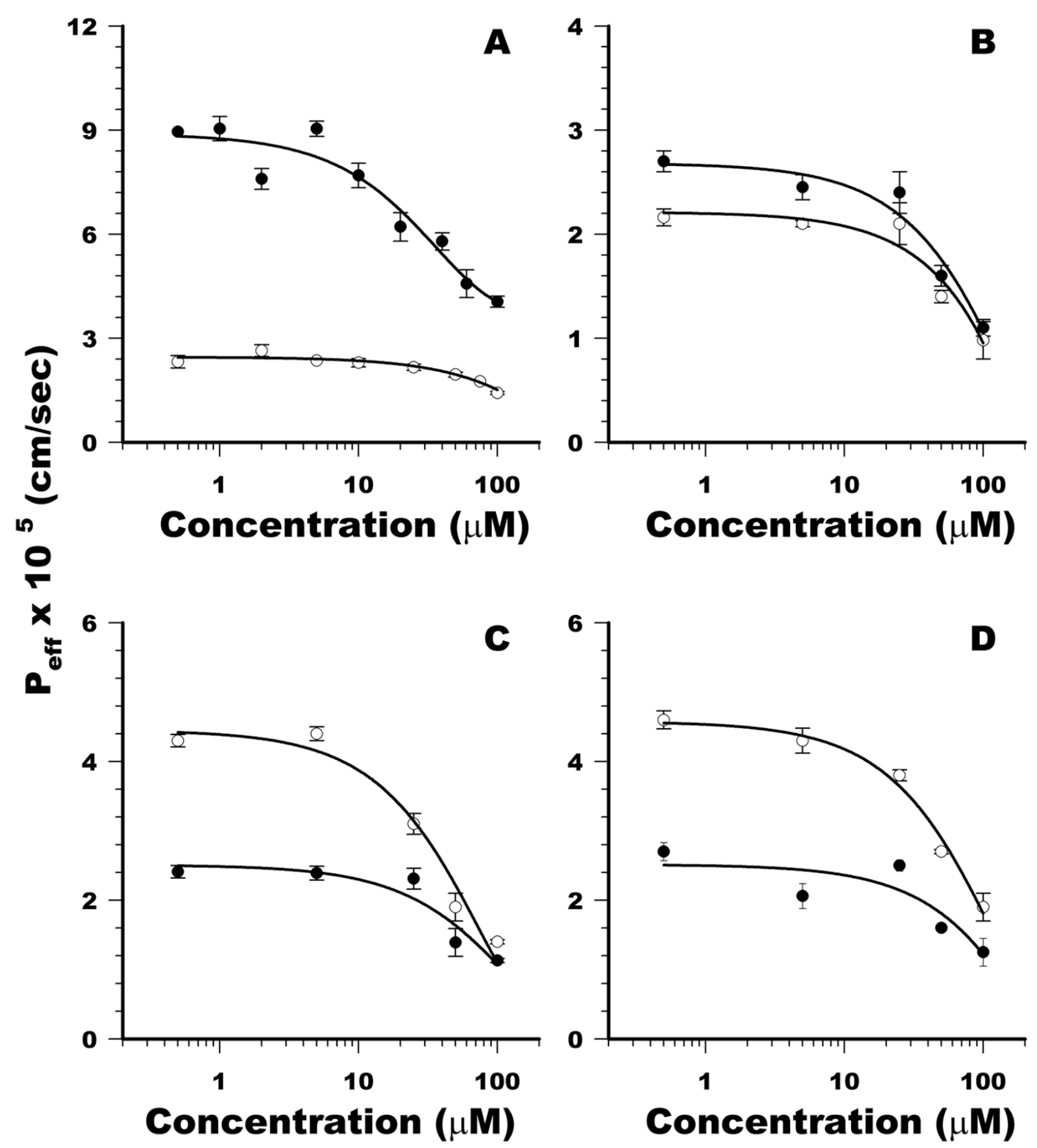

Figure I

Concentration dependence of 20-(S)-camptothecin transport across Caco-2 cells (a), MDCK II/wild type (b), MDCK II/P-glycoprotein (c) and MDCK II/Multidrug Resistance Protein 2 (d) for apical (AP) to bisolateral $(B L)$ transport $(\bullet)$ and BL to AP transport $(O)$. Plot of effective permeability $\left(P_{\text {eff }}\right)$ (mean \pm standard deviation) and the best-fit line versus logarithmic concentration. Each point represents the mean ( \pm standard deviation) for at least three observations. Michaelis-Menten parameters were determined using a weighted (I / standard deviation) nonlinear regression and are presented in Table I. 
Table I: Absorptive (apical to bisolateral) Michaelis-Menten constant $\left(K_{m}\right)$, carrier permeability $\left(P_{c}\right)$ and passive permeability $\left(P_{m}\right)$ for the transport of 20-(S)-camptothecin (CPT) across Caco-2 cells, MDCK II/wild type (wt) cells, MDCK II/P-glycoprotein (PGP) cells and MDCK II/Multidrug Resistance Protein 2 (MRP2) cells

\begin{tabular}{lllll}
\hline & Apical to bisolateral & & \\
\hline & Caco-2 & MDCK II/wt & MDCK II/PGP & MDCK II/MRP2 \\
$K_{\mathrm{m}}(\mu \mathrm{M})$ & $70.1 \pm 8.8$ & $71.5 \pm 9.7$ & $69.7 \pm 7.6$ & $101.2 \pm 17.8$ \\
$P_{\mathrm{c}}\left(\mathrm{cm} / \mathrm{s} \times 10^{5}\right)$ & $8.3 \pm 0.3$ & $2.5 \pm 0.7$ & $2.2 \pm 0.5$ & $2.5 \pm 0.4$ \\
$P_{\mathrm{m}}\left(\mathrm{cm} / \mathrm{s} \times 10^{5}\right)$ & $0.43 \pm 0.05^{\mathrm{a}}$ & Not determined & Not determined & Not determined \\
\hline
\end{tabular}

Results reported as the mean \pm standard deviation. ${ }^{\text {a }} P_{\mathrm{m}}$ was estimated as the efflux $P_{\text {eff }}$ of CPT at $4^{\circ} \mathrm{C}$.

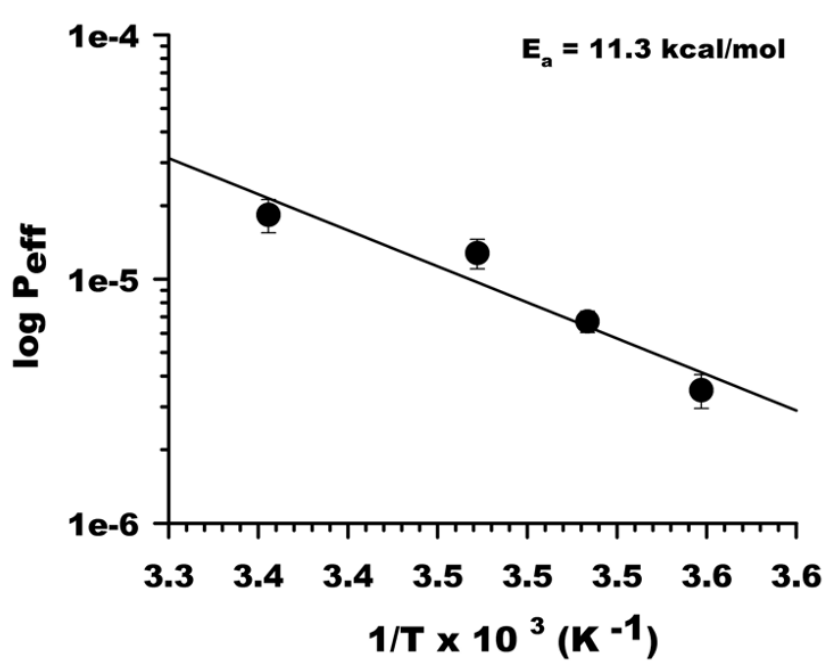

Figure 2

Temperature dependence of 20-(S)-camptothecin transport across Caco-2 cells for basolateral to apical transport. Plot of logarithmic effective permeability $\left(P_{\text {eff }}\right)$ (mean \pm standard deviation) and the best-fit line versus the reciprocal of absolute temperature. Each point represents the mean $( \pm$ standard deviation) for at least three observations. The activation energy $\left(E_{\mathrm{a}}\right)$, was determined based on the equation: slope $=$ $E_{\mathrm{a}} / 2.303 R$, where $R$ is the gas constant $(=0.001987 \mathrm{kcal} / \mathrm{deg}$ mole).

CPT was investigated in the presence of etoposide, a mixed mechanism efflux inhibitor, and GF120918, a specific PGP and BCRP inhibitor (Fig. 3). Co-incubation of etoposide with CPT reduced the efflux permeability by 1.3-fold $(200 \mu \mathrm{M})$, while in the presence of GF120918 $(0.4 \mu \mathrm{M})$ the CPT efflux was reduced by 2.1 -fold. It has been reported that GF120918 fully reverses PGP-mediated multidrug resistance at concentrations ranging from $0.05 \mu \mathrm{M}$ to $0.1 \mu \mathrm{M}$ [21]. However, in the presence of increasing concentrations of GF120918 $(0.8-1.2 \mu \mathrm{M}$, data not shown), where PGP activity is expected to be fully

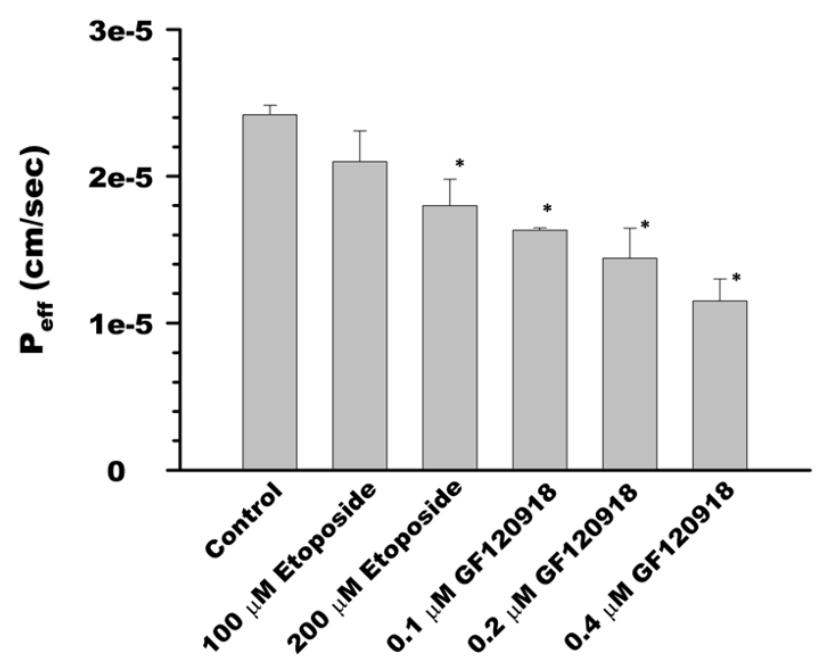

Figure 3

Inhibition of 20-(S)-camptothecin ( $10 \mu \mathrm{M})$ efflux transport across Caco-2 cells. Each point represents the mean ( \pm standard deviation) for at least three observations. * Efflux permeability (with inhibitor) is significantly different from the control (without inhibitor), $P<0.05$. $P_{\text {eff, }}$ effective permeability.

reversed, the efflux of CPT was not further reduced. This suggests that other transporters may also be involved in the transport of CPT.

The efflux inhibition kinetics of CPT were determined by investigating the BL to AP permeability of CPT at various substrate and inhibitor concentrations. For etoposide, concentrations ranging from $100 \mu \mathrm{M}$ to $200 \mu \mathrm{M}$ were selected as the $K_{\mathrm{m}}$ value of etoposide was estimated to be $\sim 213 \mu \mathrm{M}$ in our laboratory [22]. The $K_{\mathrm{m}}$ values of CPT in the presence of increasing concentrations of etoposide were determined from the Lineweaver-Burk plot $\left(K_{\mathrm{m}}=\right.$ slope / intercept) (Fig. 4a). In the absence of etoposide, 

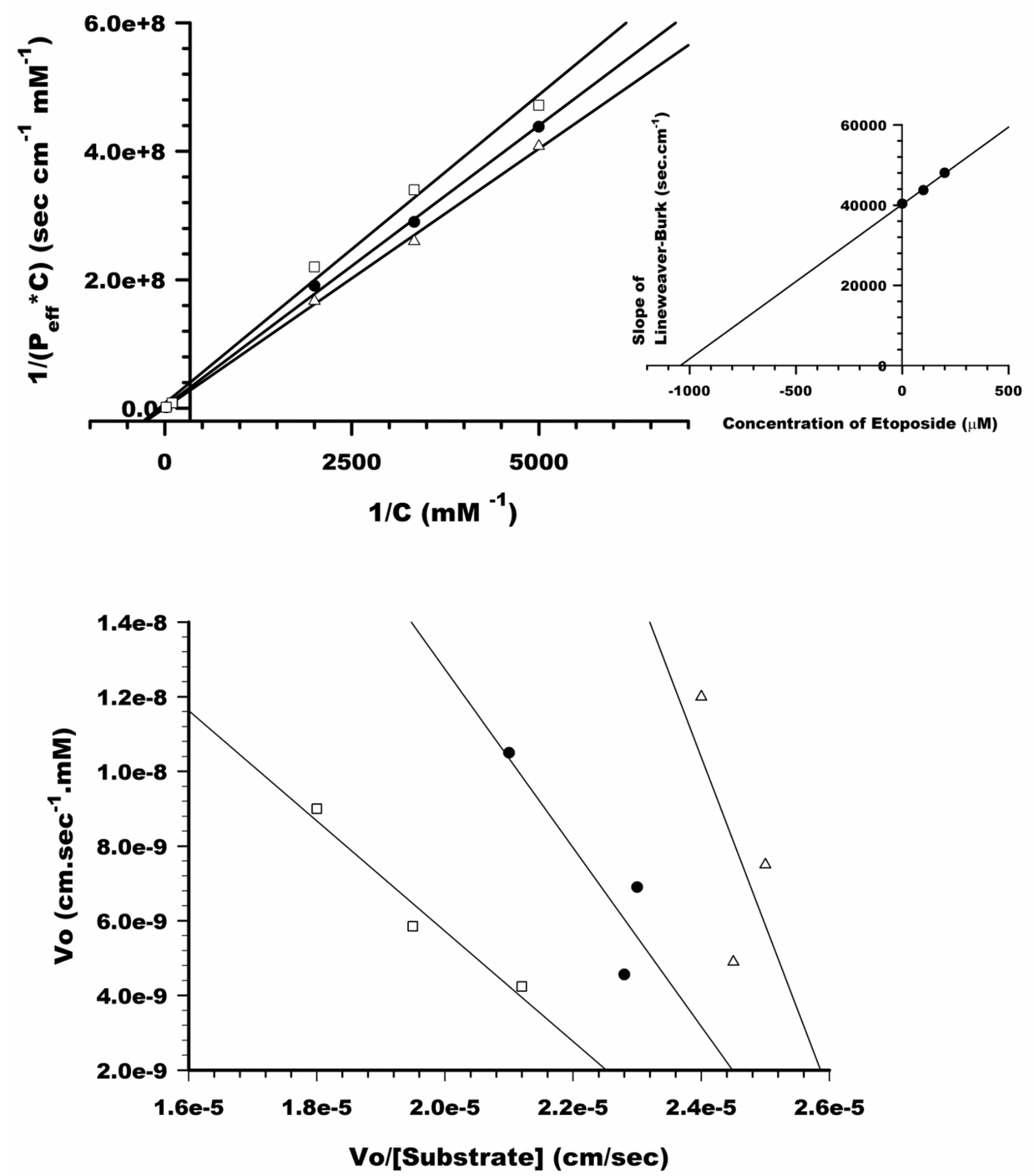

Figure 4

Lineweaver-Burk plot (a) and Eadie-Hofstee plot (b) of inhibition of 20-(S)-camptothecin efflux across Caco-2 cells at fixed etoposide concentrations of $0 \mu \mathrm{M}(\Delta), 100 \mu \mathrm{M}(\bullet)$ and $200 \mu \mathrm{M}(\square)$. Each point represents the mean ( \pm standard deviation) for at least three observations. The inhibition constant $\left(K_{i}\right)$ was determined from a secondary plot (inset) of the slopes of Lineweaver-Burk plots for various inhibitor concentrations. $P_{\text {eff }}$, effective permeability; $V_{0}$, initial rate. 
Table 2: Secretory (bisolateral to apical) Michaelis-Menten constant $\left(K_{m}\right)$, carrier permeability $\left(P_{c}\right)$ and passive permeability $\left(P_{m}\right)$ for transport of 20-(S)-camptothecin (CPT) across Caco-2 cells, MDCK II/wild type (wt) cells, MDCK II/P-glycoprotein (PGP) cells and MDCK II/Multidrug Resistance Protein 2 (MRP2) cells

\begin{tabular}{|c|c|c|c|c|}
\hline & \multicolumn{4}{|c|}{ Bisolateral to apical } \\
\hline & Caco-2 & MDCK II/wt & MDCK II/PGP & MDCK II/MRP2 \\
\hline$K_{m}(\mu M)$ & $132.9 \pm 12.2$ & $81.3 \pm 14.6$ & $36.3 \pm 7.5$ & $65.8 \pm 6.7$ \\
\hline$P_{\mathrm{c}}\left(\mathrm{cm} / \mathrm{s} \times 10^{5}\right)$ & $2.1 \pm 0.1$ & $2.0 \pm 0.2$ & $4.1 \pm 0.4$ & $4.3 \pm 0.7$ \\
\hline$P_{\mathrm{m}}\left(\mathrm{cm} / \mathrm{s} \times 10^{5}\right)$ & $0.35 \pm 0.04^{a}$ & Not determined & Not determined & Not determined \\
\hline
\end{tabular}

Results reported as the mean \pm standard deviation. a $P_{m}$ was estimated as the efflux $P_{\text {eff }}$ of $C P T$ at $4^{\circ} \mathrm{C}$.

the $K_{\mathrm{m}}$ value of CPT was $173.2 \mu \mathrm{M}$ using the LineweaverBurk plot, which is different from that obtained using nonlinear regression $(132 \mu \mathrm{M})$. The use of linearization techniques to analyze nonlinear data is well known to introduce error into the parameter $\left(K_{\mathrm{m}}, V_{\max ^{\prime}} J_{\max }\right)$ estimates. The linearization techniques were therefore only used in a qualitative manner to show the kinetic behavior of the inhibitors with CPT.

To further confirm the type of inhibition, Eadie-Hofstee plots were also constructed (Fig. $4 \mathrm{~b}$ ). The $K_{\mathrm{m}}$ values of CPT in the presence of etoposide were also found to be different from those obtained using nonlinear regression. This further demonstrates that linearization of the data can result in inconsistencies, making it difficult to conclusively determine the type of inhibition. The inhibition constant $K_{\mathrm{i}}$ was obtained from the intercept of the doublereciprocal of the Lineweaver-Burk plot (Fig. 4a, inset). The inhibition of CPT secretory efflux by etoposide was found to be weak $\left(K_{\mathrm{i}}=1044.2 \pm 73.1 \mu \mathrm{M}\right)$; however, confirmation of the earlier $K_{\mathrm{i}}$ value using nonlinear regression was not possible due to the complex nature of the inhibition and the unreliability of the estimates. These results confirm that etoposide is a mixed mechanism inhibitor and the inhibition is possibly due to interactions of various types with multiple transporters.

\section{Concentration dependence of CPT transport across transfected and wt MDCK II cells}

The absorptive and secretory transport of CPT across MDCK II/wt cells was found to be concentration dependent, with the absorptive $P_{\text {eff }}$ of CPT decreasing from $2.7 \times$ $10^{-5}$ to $1.1 \times 10^{-5} \mathrm{~cm} / \mathrm{s}$ while the efflux $P_{\text {eff }}$ decreased from $2.2 \times 10^{-5}$ to $1.0 \times 10^{-5} \mathrm{~cm} / \mathrm{s}$ at concentrations ranging from 0.5 to $100 \mu \mathrm{M}$ (Fig. 1b). Complete saturation of the transporters was not attained at the highest concentration of CPT used $(100 \mu \mathrm{M})$ due to solubility limitations. In MDCK II/PGP cells and MDCK II/MRP2 cells, transport of CPT was concentration dependent $(0.5-100 \mu \mathrm{M})$ in both the AP to BL and the BL to AP directions (Fig. 1c,1d). The secretory $P_{\text {eff }}$ of CPT decreased from $4.7 \times 10^{-5}$ to $2.0 \times 10^{-}$ $5 \mathrm{~cm} / \mathrm{s}$ across MDCK II/PGP cells and from $4.5 \times 10^{-5}$ to
$1.4 \times 10^{-5} \mathrm{~cm} / \mathrm{s}$ across MDCK II/MRP2 cells, and it was approximately twofold greater than that observed across MDCKII/wt cells (Table 2).

The efflux ratio of permeabilities (BL-AP/AP-BL) of CPT in MDCK II/wt cells was approximately 1 while the ratios in MDCK II/PGP cells and MDCK II/MRP2 cells were greater than 1, confirming that the transfected gene products dominated the transport behavior as compared with the endogenous canine transporters. These results correlate well with the increased expression levels of PGP and MRP2 in MDCK II/PGP and MDCK II/MRP2 cells, respectively, relative to MDCK II/wt cells (Fig. 5) and suggest that these transporters are possibly involved in the secretory efflux of CPT.

\section{Inhibition of CPT secretory permeability across MDCK II cells}

To determine the extent to which PGP and MRP2 are involved in the efflux of CPT, CPT transport was investigated in the presence of GF120918, a specific PGP and BCRP inhibitor, and in the presence of MK571, a potent MRP family inhibitor, using MDCK II/PGP cells and MDCK II/MRP2 cells, respectively. In the presence of GF120918 $(0.2 \mu \mathrm{M})$ the absorptive transport of CPT across MDCK II/PGP cells increased by 52\% while efflux decreased by $31 \%$ (Fig. 6a). The incomplete reversal of the efflux ratio (3.36 to 1.49) implies that either PGP was not completely inhibited by GF120918 at the dose investigated or that another transporter may be present and play a role in the efflux of CPT.

In MDCK II/MRP2 cells, the absorptive transport of CPT increased by 33\% while secretory permeability decreased by $\sim 35 \%$ in the presence of MK571 (200 $\mu \mathrm{M})$ (Fig. 6b). The efflux ratio was completely reversed (2.31 to 1.03 ), suggesting that MK571 completely inhibited MRP2.

These results further confirmed the involvement of PGP and MRP2 in the efflux of CPT. 

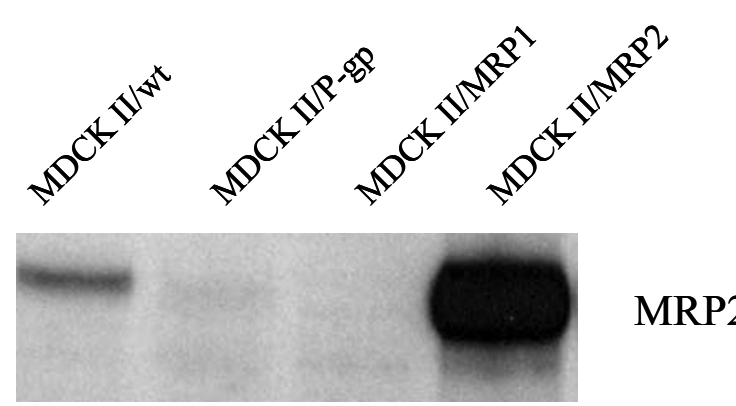

MRP2

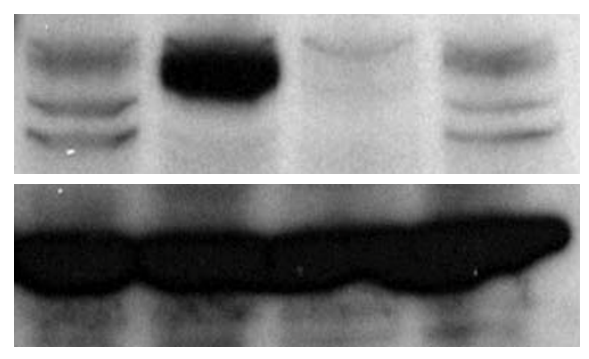

P-gp

$\beta$-Actin

\section{Figure 5}

Overexpression of P-glycoprotein (PGP) and Multidrug Resistance Protein 2 (MRP2) in MDCK II cells using western blot analysis. Ten milligrams of protein of each cell lysate were size fractionated in a polyacrylamide gel containing SDS. Blots of the gel were incubated with antibodies to PGP (C219) and MRP2 (MRP2 H-I7), followed by enzyme-linked anti-mouse or anti-goat antibodies, respectively. The images were then developed by enhanced chemiluminescence.

\section{Discussion}

Clinical resistance to chemotherapeutic drugs is a major obstacle in the treatment of cancer. The ATP-binding cassette (ABC) family of membrane transporters has been strongly implicated in the development of resistance, and numerous studies have been conducted in an attempt to identify structural specifications for these transporters. The roles of these transporters in limiting the absorption and disposition of drugs, however, have not been extensively studied. In the present study we investigated the role of two of the ABC transporters involved in multidrug resistance (MDR), namely PGP and the multidrug resistance associated protein 2 (MRP2/CMOAT), on the absorptive and secretory permeability of CPT. The roles of MRP1, MRP3 and BCRP on the permeability of CPT were not specifically addressed in this study. However, ongoing studies in our laboratory are evaluating the potential role of these transporters on the absorption and disposition of the CPTs.

Since our initial goal was to elucidate the roles of membrane transporters in the absorption of CPT, we use 'absorptive' to indicate net transport in the $\mathrm{AP}$ to $\mathrm{BL}$

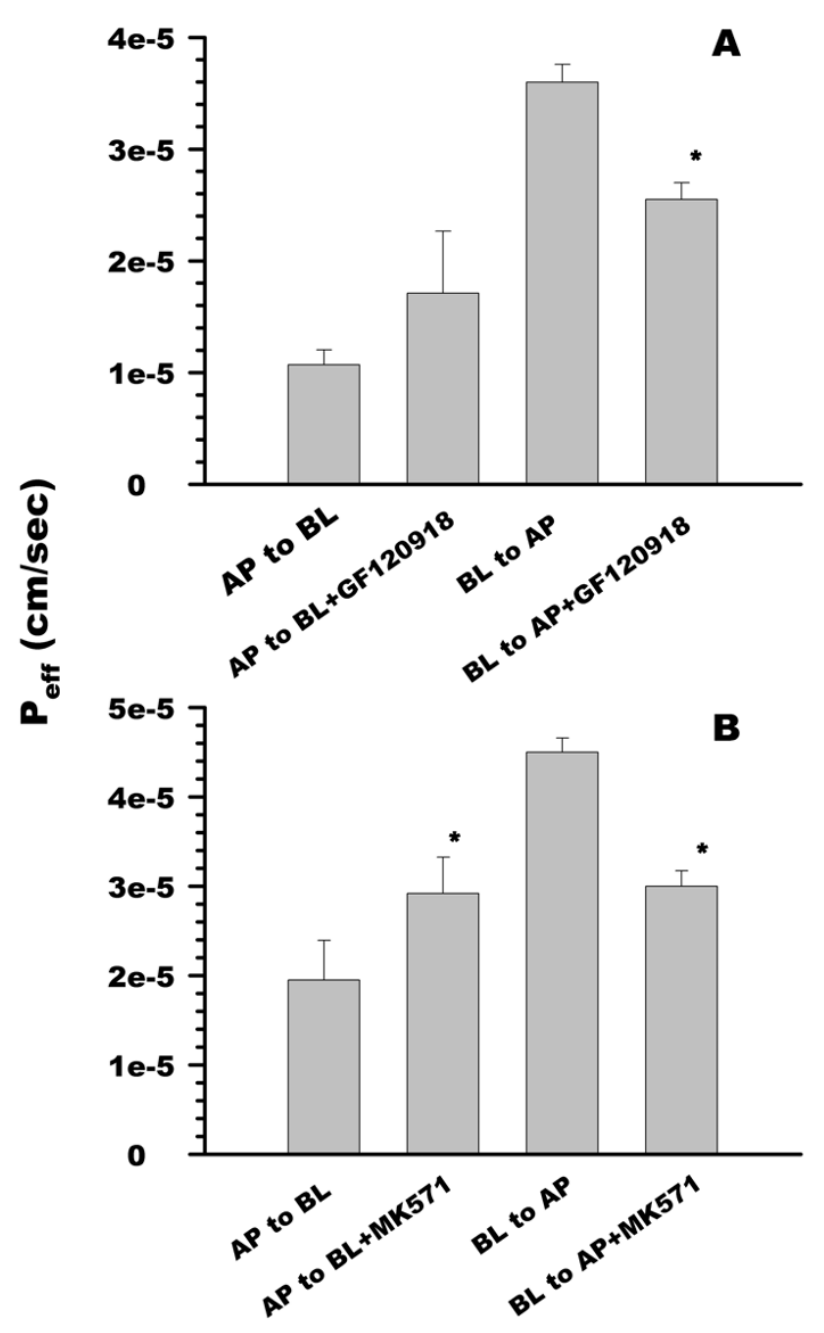

Figure 6

Inhibition of 20-(S)-camptothecin efflux transport across MDCK II/P-glycoprotein (PGP) cells in the presence of GFI $20918(0.2 \mu \mathrm{M})(\mathrm{a})$, and across MDCK II/Multidrug Resistance Protein 2 (MRP2) cells in the presence of MK57I $(200 \mu \mathrm{M})$ (b). Each point represents the mean ( \pm standard deviation) for at least three observations. * Efflux permeability (with inhibitor) is significantly different from the control (without inhibitor), $P<0.05$. AP, apical; BL, bisolateral, $P_{\text {eff }}$, effective permeability.

direction and we use 'secretory' to indicate net BL to AP transport. The absorptive and secretory permeabilities of CPT were initially evaluated in Caco- 2 cells, a well-characterized model for studying the intestinal transport of drugs. Given the multiplicity of membrane transporters in Caco- 2 cells and the lack of specific transport inhibitors, the overall mechanistic value of the Caco- 2 results is questioned. However, given the wide use of Caco- 2 cells as a 
standard for assessing the absorption potential of drugs, the current results are a valuable addition to that ever growing database. In addition, the Caco-2 results provided a rationale for further mechanistic studies using the MDCK II cell lines.

Numerous transporters have been implicated in the efflux of the camptothecin analogs (CPT-11 and TPT), including PGP [23], MRP2 [24], MRP1 and BCRP [16] from cells. These transporters are overexpressed in tumor cell lines, displaying cross-resistance to a broad range of structurally and functionally unrelated drugs [25]. BCRP, PGP, and MRP2 are apically localized on the epithelial cells in normal tissues, such as the intestine, kidney and liver, where they are believed to mediate drug secretion and efflux in the intestine and liver, possibly influencing net absorption and body and cellular disposition. In comparison with PGP, the role of MRP2 on drug pharmacokinetic profiles is not as well characterized. The transport of CPT was therefore evaluated across MDCK II cells transfected with the MDR and MRP2 genes.

The absorptive $P_{\mathrm{c}}$ of CPT across MDCK II/wt cells, MDCK II/PGP cells and MDCK II/MRP2 cells was found to be similar, possibly due to the presence of endogenous MRP1 located on the basolateral membrane and the lack of specialized influx transporters on the AP domain. In Caco-2 cells, however, the absorptive permeability (AP$\mathrm{BL}$ ) of CPT was significantly higher, suggesting the possible involvement of an absorptive transporter for CPT. It is also possible that the results could be explained by differences in the types of transporters expressed or expression levels. For example, one possible mechanism may be that a higher level of MRP1 activity in Caco- 2 cells led to enhanced CPT efflux in the absorptive direction. These results also imply that passive diffusion may not be solely responsible for the absorption of CPT.

The secretory permeability of CPT was comparable in Caco- 2 cells and in MDCK II/wt cells; however, it was approximately twofold greater (Table 1) in MDCK II/PGP cells and MDCK II/MRP2 cells. This result clearly implicates endogenous transporters in the secretion of CPT from MDCK II/wt cells. It is difficult to assess which endogenous transporters may be involved, but recent work in our laboratory using these cell lines demonstrates the presence and activity of endogenous canine PGP, MRP1, and MRP2 [17]. Since the efflux ratio of CPT was greater than 1 in MDCKII cells overexpressing PGP and MRP2, compared with MDCKII wt cells, the current results show that the overexpressed human transporters had a higher activity than the endogenous transporters, and an adequate signal to noise ratio was achieved allowing us to discern transport relationships for CPT with PGP and MRP2. The $K_{\mathrm{m}}$ value was approximately twofold lower across MDCK II/PGP cells than across MDCK II/ MRP2 cells, indicating that CPT has a higher affinity for the PGP transporter. This is consistent with a previous report that suggests that PGP and MRP2 are likely to be the high-affinity and low-affinity transporters, respectively, for CPT and its analog CPT-11 [23].

MDCKII cells are derived from the dog kidney while Caco2 cells are of human colonic origin. These differences in species and organ location of origin could imply potentially large differences in the type and activity of transporters in each cell line. On a macroscopic level, on the other hand, the secretory permeability of СРT was found to be similar in Caco-2 cells and in MDCK II/wt cells (Table 2). This suggests that MDCK II/wt cells could be an attractive alternative cell model to Caco-2 cells for studying drug transport, especially since the culturing time for MDCK cells is only 3 days compared with the 21-day standard for Caco- 2 cells.

Most of the studies to date investigating the multidrug resistance phenomenon have been conducted in cancer cells. Cellular accumulation of CPT-11, SN-38 and TPT in tumor cells overexpressing the PGP transporter was found to be reduced [26], and this reduction in cellular accumulation was reversed by PGP reversal agents [26-28]. However, conflicting reports have been published on the affinity of CPT for PGP [29-31]. The presence of a positive charge at physiological $\mathrm{pH}$ is thought to be necessary for binding to PGP. However, differing susceptibility of TPT, CPT-11 and 9-aminocamptothecin to PGP-mediated MDR and the much lower resistance levels compared with typical MDR compounds suggests that the positive charge is probably not an absolute requirement for PGP binding. In addition, these discrepancies could result from the use of cells selected for drug resistance that overexpress multiple transporters, or cell surrogates of normal human enterocytes such as Caco- 2 that contain a wide variety of transporters and metabolizing enzymes. In these systems the role of specific transporters and the interpretation of kinetic data is difficult as multiple known or unknown transporters are present. The use of cell surrogates for studying drug transport in vitro therefore presents a challenge. This can be overcome using cells engineered to overexpress certain membrane transporters, as demonstrated in this study.

Evaluating the transport of a drug in the presence of specific inhibitors can provide useful information on the role of various transporters on drug permeability. In the presence of the mixed mechanism efflux inhibitor etoposide, the secretory permeability of CPT was only weakly inhibited (apparent $K_{\mathrm{i}}=1040 \pm 131 \mu \mathrm{M}$ ). Etoposide interacts with numerous transporters (i.e. mixed mechanism), and the nature of each interaction (i.e. competitive, 
uncompetitive or noncompetitive) has not been thoroughly studied. Even though the large apparent $K_{\mathrm{m}} /$ low affinity reflects the possible interactions with numerous transporters, complete inhibition was observed. The apparent discrepancy between the Eadie-Hofstee and Lineweaver-Burk plots in characterizing the type of inhibition by etoposide is also a reflection of the possible and different types of interactions with multiple known and unknown transporters. For this reason, we chose to use cell lines that overexpress transporters of interest, PGP and MRP2, in order to increase the sensitivity of the cell model to a specific transporter interaction.

The absorptive transport of CPT across MDCK II/PGP cells increased while the secretory transport decreased in the presence of GF120918. Similarly, in MDCK II/MRP2 cells the absorptive transport of CPT increased, while efflux decreased in the presence of MK571. Although the results are qualitatively similar, the mechanisms are probably very different. For example, since PGP/BCRP are apically located, inhibition of AP efflux would be expected to increase the total AP to BL permeability while decreasing the BL to AP flux. On the other hand, the net effect of inhibiting MRP1, MRP2 and, possibly, MRP3 is less predictable since they are all efflux transporters, but MRP1 is oriented as an absorptive transporter while MRP2 and MRP3 are oriented as secretory transporters. One possible scenario is that MK571 more strongly inhibited MRP2/ MRP3 than MRP1, facilitating an increase in AP to BL permeability. However, without further mechanistic studies and highly specific inhibitors it is not possible to show this conclusively.

Due to the narrow therapeutic index for the camptothecins and the requirement for constant blood levels, low bioavailability and interpatient variability limits the viability of the oral delivery route. Although approved for parenteral use, none of the CPTs have yet received approval for oral administration. The metabolism of CPT has been evaluated in our laboratory by incubating the drug with rat intestinal and liver s9 fractions and microsomes. Minimal degradation of CPT was observed, suggesting that the first-pass metabolism is unlikely to contribute significantly to the variable bioavailability of CPT (data not shown). Elimination of CPT occurs through the biliary and urinary routes [13], and therefore the presence of PGP and MRP2 in the liver and kidney may also affect the oral bioavailability and disposition of CPT. The current results suggest that the intestinal absorption and disposition of CPT is probably mediated by several active transporters, and we specifically demonstrate the involvement of PGP and MRP2 in the efflux of CPT. This may contribute in part to the variable oral absorption of CPT [9] since the absorption of CPT occurs primarily from the ileum, which has significant drug secretion capacity compared with other regions of the gastrointestinal tract [32].

\section{Conclusions}

An appreciation of the role of transporters on the absorption and secretion of drugs is critical in understanding the poor and erratic bioavailability observed when the oral route is utilized for drug administration. The extent to which intestinal absorption and secretion contributes to the erratic bioavailability of CPT is currently unknown. The present study was therefore conducted to elucidate the role of two of the $\mathrm{ABC}$ transporters involved in MDR, namely PGP and the multidrug resistance associated protein 2 (MRP2/CMOAT), on the absorption of CPT. The study provides experimental evidence demonstrating that the in vitro secretion of CPT is mediated by the active transporters PGP and MRP2. Variation in the expression levels and activity of PGP and/or MRP2 in the intestine, liver and kidney may therefore be responsible for the inconsistent systemic availability of CPT observed in human subjects after oral administration.

\section{Competing interests}

None declared.

\section{Authors' contributions}

AKL and FRL contributed equally to the generation of data and the preparation of the manuscript. AG and SHL participated in the preparation of western blots. PVP and VV contributed to the generation of the in vitro data. ER participated in the design of the study and the interpretation of data as well as reviewing the manuscript. PJS conceived of the study, participated in its design, coordination, data analysis and interpretation, and participated in the preparation/submission of the manuscript.

\section{Acknowledgements}

This work was supported by NIH grant Al42007 and by ACS grant RPG98-057-0I-CCR.

\section{References}

I. Wang JC: DNA topoisomerases. Annu Rev Biochem 1985, 54:665-697.

2. Gottlieb JA, Guarino AM, Call JB, Oliverio VT, Block JB: Preliminary pharmacologic and clinical evaluation of camptothecin sodium (NSC-1 00880). Cancer Chemother Rep 1970, 54:46I-470.

3. Hertzberg RP, Caranfa MJ, Holden KG, Jakas DR, Gallagher G, Mattern MR, Mong SM, Bartus JO, Johnson RK, Kingsbury WD: Modification of the hydroxy lactone ring of camptothecin: inhibition of mammalian topoisomerase $I$ and biological activity. J Med Chem 1989, 32:715-720.

4. Hsiang YH, Hertzberg R, Hecht S, Liu LF: Camptothecin induces protein-linked DNA breaks via mammalian DNA topoisomerase I. J Biol Chem 1985, 260: I 4873-I4878.

5. Giovanella BC, Stehlin JS, Wall ME, Wani MC, Nicholas AW, Liu LF, Silber R, Potmesil M: DNA topoisomerase I - targeted chemotherapy of human colon cancer in xenografts. Science 1989 , 246: 1046-1048.

6. Del Bino G, Lassota P, Darzynkiewicz Z: The S-phase cytotoxicity of camptothecin. Exp Cell Res 199I, 193:27-35. 
7. Gerrits C], Burris H, Schellens JH, Eckardt JR, Planting AS, van der Burg ME, Rodriguez GI, Loos WJ, van Beurden V, Hudson I, Fields S, Von Hoff DD, Verweij J: Oral topotecan given once or twice daily for ten days: a phase I pharmacology study in adult patients with solid tumors. Clin Cancer Res 1998, 4: I I53-I I 58.

8. Houghton PJ, Cheshire PJ, Hallman JD, Lutz L, Friedman HS, Danks MK, Houghton JA: Efficacy of topoisomerase I inhibitors, topotecan and irinotecan, administered at low dose levels in protracted schedules to mice bearing xenografts of human tumors. Cancer Chemother Pharmacol 1995, 36:393-403.

9. Gupta E, Vyas V, Ahmed F, Sinko P, Cook T, Rubin E: Pharmacokinetics of orally administered camptothecins. Ann NY Acad Sci 2000, 922:195-204.

10. Drengler RL, Kuhn JG, Schaaf LJ, Rodriguez GI, Villalona-Calero MA, Hammond LA, Stephenson JA Jr, Hodges S, Kraynak MA, Staton BA, Elfring GL, Locker PK, Miller LL, Von Hoff DD, Rothenberg ML: Phase I and pharmacokinetic trial of oral irinotecan administered daily for 5 days every 3 weeks in patients with solid tumors. J Clin Oncol 1999, 17:685-696.

II. Schellens JH, Creemers G], Beijnen JH, Rosing H, Boer-Dennert M, McDonald M, Davies B, Verweij J: Bioavailability and pharmacokinetics of oral topotecan: a new topoisomerase I inhibitor. $\mathrm{Br}$ J Cancer 1996, 73: |268-I27I.

12. Verschraegen CF, Natelson EA, Giovanella BC, Kavanagh JJ, Kudelka AP, Freedman RS, Edwards CL, Ende K, Stehlin JS: A phase I clinical and pharmacological study of oral 9-nitrocamptothecin, a novel water-insoluble topoisomerase I inhibitor. Anticancer Drugs 1998, 9:36-44.

13. Scott DO, Bindra DS, Sutton SC, Stella VJ: Urinary and biliary disposition of the lactone and carboxylate forms of 20(S)-camptothecin in rats. Drug Metab Dispos 1994, 22:438-442.

14. Ma J, Maliepaard M, Nooter K, Loos WJ, Kolker HJ, Verweij J, Stoter G, Schellens JH: Reduced cellular accumulation of topotecan: a novel mechanism of resistance in a human ovarian cancer cell line. Br J Cancer 1998, 77:1645-1652.

15. Yang CJ, Horton JK, Cowan KH, Schneider E: Cross-resistance to camptothecin analogues in a mitoxantrone-resistant human breast carcinoma cell line is not due to DNA topoisomerase I alterations. Cancer Res 1995, 55:4004-4009.

16. Rajendra R, Gounder MK, Saleem A, Schellens JH, Ross DD, Bates SE, Sinko PJ, Rubin EH: Differential effects of the breast cancer resistance protein on the cellular accumulation and cytotox icity of 9-aminocamptothecin and 9-nitrocamptothecin. Cancer Res 2003, 63:3228-3233.

17. Williams GC, Liu A, Knipp G, Sinko PI: Direct evidence that saquinavir is transported by multidrug resistance-associated protein (MRPI) and canalicular multispecific organic anion transporter (MRP2). Antimicrob Agents Chemother 2002, 46:3456-3462

18. Liang E, Proudfoot J, Yazdanian M: Mechanisms of transport and structure-permeability relationship of sulfasalazine and its analogs in Caco-2 cell monolayers. Pharm Res 2000, 17:1168-1174

19. Gupta E, Luo F, Lallo A, Ramanathan S, Vyas V, Rubin E, Sinko P: The intestinal absorption of camptothecin, a highly lipophilic drug, across Caco-2 cells is mediated by active transporter(s). Anticancer Res 2000, 20:1013-1016.

20. Hidalgo IJ, Borchardt RT: Transport of a large neutral amino acid (phenylalanine) in a human intestinal epithelial cell line: Caco-2. Biochim Biophys Acta 1990, 1028:25-30.

21. Hyafil F, Vergely C, Du P Vignaud, Grand-Perret T: In vitro and in vivo reversal of multidrug resistance by GFI 209/8 an acridonecarboxamide derivative. Cancer Res 1993, 53:4595-4602.

22. Makhey VD, Guo A, Norris DA, Hu P, Yan J, Sinko PJ: Characterization of the regional intestinal kinetics of drug efflux in rat and human intestine and in Caco-2 cells. Pharm Res 1998, I5: I I60-II67.

23. Chu $X Y$, Kato $Y$, Sugiyama $Y$ : Possible involvement of P-glycoprotein in biliary excretion of CPT-II in rats. Drug Metab Dispos 1999, 27:440-44I.

24. Sugiyama $Y$, Kato $Y$, Chu $X$ : Multiplicity of biliary excretion mechanisms for the camptothecin derivative irinotecan (CPT-II), its metabolite SN-38, and its glucuronide: role of canalicular multispecific organic anion transporter and Pglycoprotein. Cancer Chemother Pharmacol 1998, 42(Suppl):S44-S49.
25. Bellamy WT: P-glycoproteins and multidrug resistance. Annu Rev Pharmacol Toxicol 1996, 36: 16I-183.

26. Hendricks CB, Rowinsky EK, Grochow LB, Donehower RC, Kaufmann SH: Effect of P-glycoprotein expression on the accumulation and cytotoxicity of topotecan (SK\&F 104864), a new camptothecin analogue. Cancer Res 1992, 52:2268-2278.

27. Jansen WJ, Hulscher TM, Ark-Otte J, Giaccone G, Pinedo HM, Boven $\mathrm{E}$ : CPT-I I sensitivity in relation to the expression of PI70glycoprotein and multidrug resistance-associated protein. $\mathrm{Br}$ J Cancer 1998, 77:359-365.

28. Vanhoefer U, Muller MR, Hilger RA, Lindtner B, Klaassen U, Schleucher N, Rustum YM, Seeber S, Harstrick A: Reversal of MDR Iassociated resistance to topotecan by PAK-200S, a new dihydropyridine analogue, in human cancer cell lines. $\mathrm{Br} /$ Cancer 1999, 81: | 304-|310.

29. Chen AY, Yu C, Potmesil M, Wall ME, Wani MC, Liu LF: Camptothecin overcomes MDRI-mediated resistance in human KB carcinoma cells. Cancer Res 1991, 5 I:6039-6044.

30. Hoki Y, Fujimori A, Pommier Y: Differential cytotoxicity of clinically important camptothecin derivatives in P-glycoproteinoverexpressing cell lines. Cancer Chemother Pharmacol 1997, 40:433-438

3I. Mattern MR, Hofmann GA, Polsky RM, Funk LR, McCabe FL, Johnson RK: In vitro and in vivo effects of clinically important camptothecin analogues on multidrug-resistant cells. Oncol Res 1993, 5:467-474.

32. Mouly S, Paine MF: P-glycoprotein increases from proximal to distal regions of human small intestine. Pharm Res 2003, 20:1595-1599.

\section{Pre-publication history}

The pre-publication history for this paper can be accessed here:

http://www.biomedcentral.com/1741-7015/2/16/prepub
Publish with Biomed Central and every scientist can read your work free of charge

"BioMed Central will be the most significant development for disseminating the results of biomedical research in our lifetime. "

Sir Paul Nurse, Cancer Research UK

Your research papers will be:

- available free of charge to the entire biomedical community

- peer reviewed and published immediately upon acceptance

- cited in PubMed and archived on PubMed Central

- yours - you keep the copyright
BiolMedcentral 